\title{
New JWS Board Members Share Their Vision and coals for the Future
}

\section{Kaitlin Calva}

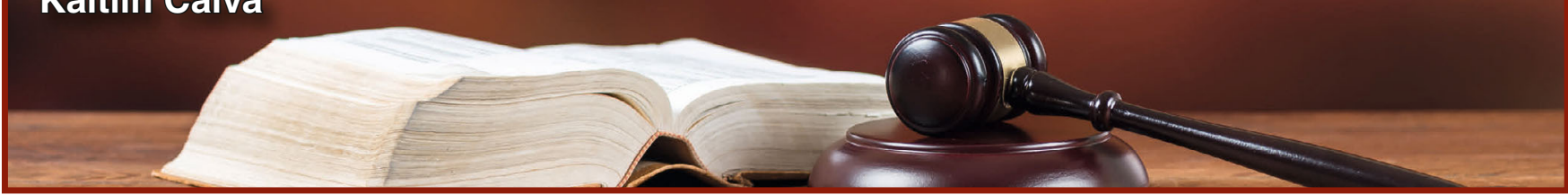

They see the value that thought-provoking technical programming has on advancing an academic and professional career. They understand the significance of creating lasting relationships through attending conferences and meeting new people. And, they all know that now it is their turn to engage with fellow TMS members and give back to the Society through service on the Board of Directors.
Each of the following five individuals has a unique story, perspective, and set of experiences that will help to lead TMS into the future. Before they officially take office at the TMS 2019 Annual Meeting \& Exhibition (TMS2019) in San Antonio, Texas, next March, take some time to get to know TMS's newly confirmed board members. Read on to find out more about each of them, including their hopes and goals in the years ahead as TMS leaders.

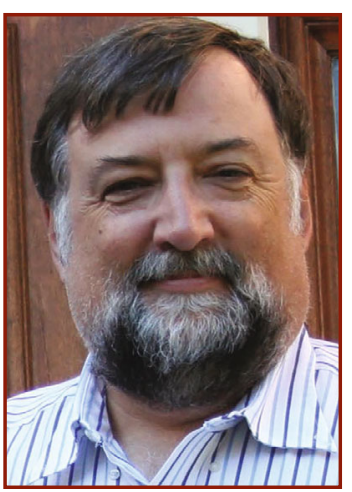

\section{Vice President Thomas Battle}

"Once involved, you tend to stay involved," noted Thomas Battle, extractive metallurgy consultant, of his time as a member of TMS so far.

Battle will begin a threeyear term on the Presidential Rotation when he is installed as Vice President at TMS2019. He will then lead the Board of Directors as 2020 President before moving to the role of Past President in 2021.

"I attended my first annual meeting in 1982 while in graduate school. To both my master's thesis advisor, John Hager, and my doctoral advisor, Robert Pehlke, it was important to my development as a student and an engineer that I attend TMS meetings and make presentations," Battle said. Since his days as a student at the Colorado School

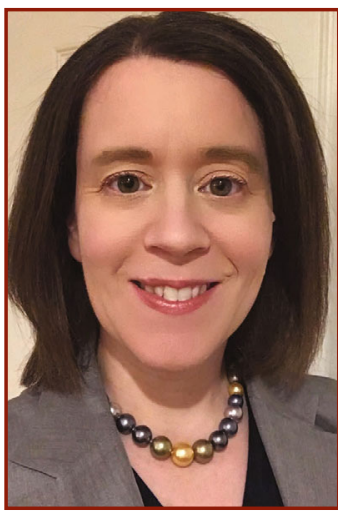

\section{Membership \& Student Development Director Alexis C. Lewis}

"TMS's structure of bottomup programming was one of the positive features that kept me involved," said Alexis C. Lewis, program director, National Science Foundation. "I was able to help organize symposia early in my career and then become more active in technical committees." of Mines, Battle has been an active member for 30 years, participating on various technical and functional committees and eventually serving as Extraction \& Processing Division (EPD) Chair from 2008 to 2011. Now, he says that seeing younger members - some of whom Battle's even mentored himself - take on leadership roles within his home division and across TMS, has been a highlight of his membership. Additionally, receiving the 2014 EPD Distinguished Service Award for his efforts in supporting the division was a particularly memorable occasion.

Battle says he's "up to the challenge" of interacting with other organizations and leading the Society and the field into the future during his upcoming term on the Board. "I hope to improve TMS's standing in the world of engineering/ scientific professional societies, adding to the efforts made in recent years to interact more closely with societies around the world." He also commented that he is looking forward to working with other Board members, both old friends and new. "I'm hoping to get further acquainted with people and ideas from other divisions I haven't worked with before."
This initial encouragement helped Lewis get more involved in the Society, serving on a variety of committees and receiving the 2013 Structural Materials Division (SMD) Young Leaders Professional Development Award over the course of her 15-year membership. Eventually, she also began organizing specialty conferences - the First International Congress on 3D Materials Science (3DMS 2012) and later the First Summit on Diversity in the Minerals, Metals, and Materials Professions (DMMM1) in 2014. Lewis noted her time working on the 3DMS congress "was one of the most rewarding experiences with TMSthe 3DMS community has grown and evolved in exciting ways since that first conference, and it's been wonderful to 
watch that evolution." Also exciting was her experience on the DMMM1 organizing committee. 'I've attended all three summits and each time learned a lot about myself. The most recent summit added new elements, built on the success of the first two, and it's been so educational and inspiring."

Looking back, Lewis identified her time as a member and vice-chair of the Membership and Student Development Committee as an eye-opening experience that will influence her next position as a member of the Board. "TMS has been a great resource for me from a technical standpoint, as well as through many networking and professional development activities. I am glad to be able to give back to the Society through service on the Board." She continued: "I am really looking forward to working with the Board to continue and expand the Society's efforts, and I hope I can contribute some new perspectives of my own."

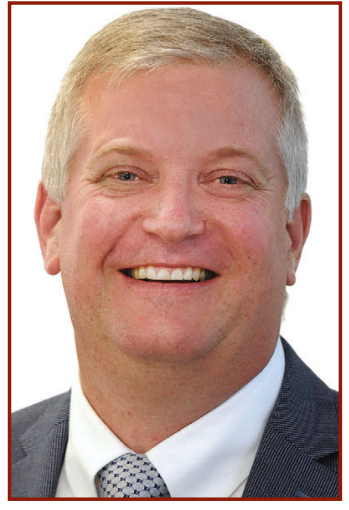

\section{Light Metals Division Chair Eric Nyberg}

"It is an honor to be involved with an international organization that has its fingertips on the state-of-the-art materials research, making a difference technically, politically, and hopefully socially as well," said Eric Nyberg, Director of Programmes at Brunel University London.

Nyberg first became involved with TMS as a session monitor during his undergraduate days. Since then, he noted that attending meetings has remained a vital aspect of his membership. "TMS conferences allow you to learn so much about the latest developments in a few short days. They have enabled me to network with individuals from around the world in a relatively small field of lightweight alloys. Many have become lifelong acquaintances, colleagues, and friends."
After working within the Society's Light Metals Division (LMD) for nearly 30 years in a variety of positions (most notably in helping to establish the Magnesium Committee and receiving the 2012 LMD Distinguished Service Award), Nyberg is ready to take on his newest role as LMD Chair. "I felt it was a good time for me to explore how I could continue to grow professionally by volunteering for more and broader responsibilities," he said.

As a member of the Board, Nyberg hopes to effect change on the issues of diversity and inclusion and international engagement. "Diversity in the technical fields is critical. The world is a much smaller place than it used to be and we must engage all of our members," he stated. "TMS is making a difference in becoming more diverse in many ways and I am happy to promote this. I personally hope that I can contribute toward increased involvement from our international members and underrepresented minorities. I hope that I can help TMS continue to be a leader in professional and technical societies, particularly when it comes to a diverse spectrum of active members volunteering for leadership roles."

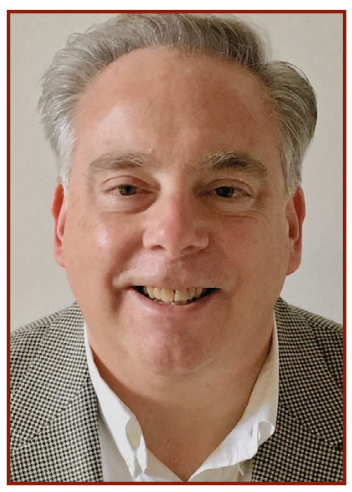

\section{Materials Processing \& Manufacturing Division Chair Mark R. Stoudt}

Mark R. Stoudt, materials research engineer at the National Institute of Standards and Technology (NIST), has been a TMS member since 1983 and understands exactly how taking an active role in the Society can help one grow professionally. "Early on, TMS opened doors and allowed me to learn from more established people in our field. Now that I am established, my committee activities allow me to work with remarkable people to enrich our Society."

As a longtime member of the Materials Processing \& Manufacturing Division (MPMD), Stoudt will bring his experience as a committee member and chair to the table as he heads the division in the coming years. "My entire perception of TMS membership changed after being elected to the leadership of the Shaping and Forming Committee," he recalled. "When I became the chair, being a part of the MPMD Council gave me a truer sense of how a technical division functions and how important the role of technical programming is to the overall success of the division."

Stoudt is ready to advance both the division and the entire Society into the future through his move from vice-chair to MPMD Chair. "The MPMD has a rich history of addressing important scientific issues through a combination of an extraordinarily dedicated committee leadership and strong technical programming, and I hope that I will be able to continue in that tradition of excellence." He further expressed his overall excitement for helping all members of TMS to learn and grow with him: "I am really looking forward to working with the Board, and the members of the MPMD Council to continue to strengthen our Society, attract new members to our technical committees, and to make membership in TMS as rewarding as possible." 


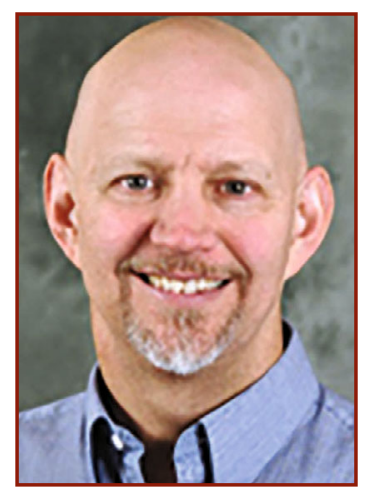

\section{Structural Materials Division Chair Daniel Miracle}

"I've admired the commitment, professionalism, and talent of my peers as one by one they chose to take on volunteer leadership positions in TMS. Like mentoring from a distance, I've watched as they contributed to our profession. These volunteers have inspired me to do more in my career and gave me a template to follow when I was ready," said Daniel Miracle, senior scientist, Air Force Research Laboratory, of taking on greater responsibility within the Society.

"My TMS involvement is driven by the strong desire to give back to the Society and the community." In over 40 years of engaging in Society activities, Miracle still recognizes and values the importance that forming personal connections can have, and hopes he can help other members grow in this way as well. "I was drawn to the programming that helped develop my technical knowledge," he recalled of his early days of attending meetings as an undergraduate student. "After some years, I found that I spent more time at TMS conferences meeting new people with fresh ideas, having hallway discussions, and building collaborations. This has become an essential part of my career."

Throughout his membership in TMS, Miracle participated in several committees before serving as the current vice-chair of the Structural Materials Division (SMD) and was named a 2018 TMS Fellow. Going forward, he hopes to bring these experiences to help the Board address issues facing the field today. "TMS has established a strong profile of leadership that enables new opportunities for our profession and our Society, but there are also many challenges. This is a great time to help the Society move into new ways of doing business that can contribute to our profession and to help improve the human condition."

\section{Are You the Next Member of the TMS Board of Directors?}

\section{TMS is accepting nominations for four Board of Directors positions for the 2020-2023 term} until January 15, 2019. The open positions are: Presidential Rotation; Content Development \& Dissemination; Professional Development; and Public \& Governmental Affairs. Additionally, positions for Extraction \& Processing Division and Functional Materials Division are also open on the 2020-2023 Board of Directors, but nominations are being developed directly through the technical divisions.

The Presidential Rotation encompasses three successive one-year positions: Vice President, President, and Past President. All three roles are officer positions with the Society and carry unique responsibilities. The role of President includes serving as the chair of the Board of Directors.

The Content Development \& Dissemination chair guides the management and development of TMS content initiatives, inclusive of journals, books, e-resources, and other media. This role is also responsible for growing content-related strategic and revenue opportunities and protecting and building the TMS brand as a provider of content to the science and engineering community.

The Professional Development chair represents the entire membership in carrying out the professional activities of the Society concerned with professional development, professional registration, education, and accreditation.

The Public \& Governmental Affairs chair serves the entire membership through planning,

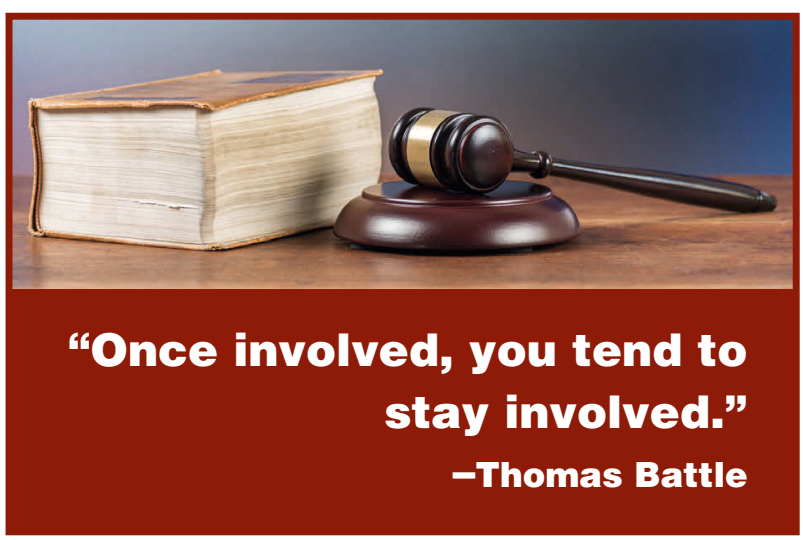

coordinating, executing, monitoring, and supporting the TMS role and mission in public and governmental affairs.

Packages for applicants to these positions will be considered by the Society's Nominating Committee, which will then recommend a candidate for each position to the Board of Directors.

If approved by the Board of Directors, these endorsed candidates will be presented to the general membership for approval by July 2019 .

To access complete job descriptions and qualifications for each office, as well as the Nominee Statement Form and nomination instructions, visit the TMS website at www.tms.org and select the Board Nominations page in the Society Governance section (found under the About tab in the main menu). For additional information, contact Deborah Hixon, TMS Award Program Administrator, at hixon@ @ms.org.

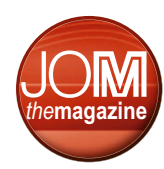

